Revista Baiana de Saúde Pública
ARTIGO ORIGINAL DE TEMA LIVRE

\section{ENTREVISTA MOTIVACIONAL COMO UMA FERRAMENTA NO PROCESSO DE TRABALHO DO AGENTE COMUNITÁRIO DE SAÚDE}

\author{
Gabriela de Luca Meyer \\ Ramona Fernanda Ceriotti Toassi ${ }^{b}$ \\ Elisabeth Meyer ${ }^{c}$ \\ Daniel Demétrio Faustino-Silva ${ }^{d}$
}

\title{
Resumo
}

A entrevista motivacional (EM) caracteriza-se como uma forma refinada de guiar uma conversa por meio de estratégias específicas que buscam estimular mudanças de comportamento. Esta pesquisa teve como objetivo compreender a apropriação dos conceitos e técnicas da EM por agentes comunitários de saúde após treinamento específico realizado em um serviço de atenção primária à saúde (APS) no Sul do Brasil. Trata-se de um estudo de abordagem qualitativa que incluiu a participação de agentes comunitários de saúde (ACS) em um grupo focal. O material textual produzido foi analisado pela técnica da análise temática de conteúdo. As três categorias que emergiram do grupo focal destacaram expectativas e lembranças do treinamento em conceitos de EM, com significados para o trabalho do ACS, e suas possibilidades e desafios. Os ACS expressaram conexões dos aprendizados durante treinamento às situações de trabalho e de vida pessoal. Desafios foram identificados na aplicação da EM por questões relacionadas ao tempo para realizar uma visita domiciliar, à intensa demanda no trabalho diário, às mudanças no processo de

a Odontóloga. Especialista em Saúde da Família e Comunidade. Residente Multiprofissional em Saúde no Grupo Hospitalar Conceição. Porto Alegre, Rio Grande do Sul, Brasil.E-mail: gabidmeyer@gmail.com

b Odontóloga. Doutora em Educação. Professora Adjunta da Faculdade de Odontologia e do Programa de Pós-Graduação em Ensino na Saúde da Universidade Federal do Rio Grande do Sul. Porto Alegre, Rio Grande do Sul, Brasil.E-mail: ramona.fernanda@ufrgs.br

c Psicóloga. Doutora em Psiquiatria. Professora do Programa de Pós-Graduação em Ciências da Saúde do Instituto de Cardiologia da Fundação Universitária de Cardiologia. Porto Alegre, Rio Grande do Sul, Brasil.E-mail: to bethmeyer@hotmail.com

d Odontólogo. Doutor em Saúde Bucal Coletiva. Professor do Programa de Pós-Graduação em Avaliação de Tecnologias para o Sistema Único de Saúde no Grupo Hospitalar Conceição. Porto Alegre, Rio Grande do Sul, Brasil. E-mail: ddemetrio@gmail.com

Endereço para correspondência: Grupo Hospitalar Conceição, Gerência de Ensino e Pesquisa. Av. Francisco Trein, n. 326, Cristo Redentor. Porto Alegre, Rio Grande do Sul, Brasil. CEP: 91350-200. E-mail: ddemetrio@gmail.com 
trabalho e à realização de atividades administrativas. A EM mostrou-se uma ferramenta apropriada e viável para a prática profissional dos ACS no contexto da APS.

Palavras-chave: Entrevista motivacional. Agentes comunitários de saúde. Atenção primária à saúde. Sistema Único de Saúde.

\author{
MOTIVATIONAL INTERVIEWING AS A TOOL IN THE \\ WORK PROCESS OF THE COMMUNITY HEALTH WORKER
}

\begin{abstract}
Motivational interviewing (MI) is characterized as a refined way of guiding a conversation through specific strategies that seek to stimulate behavioral change. This study analyzed the appropriation of MI concepts and techniques by Community Health Workers after specific training performed in a Primary Healthcare $(\mathrm{PH})$ service in the South Region of Brazil. This is a qualitative study that included the participation of Community Health Workers (CHW) in a focus group. The textual material produced was analyzed by the thematic content analysis technique. The three categories that emerged from the focus group stressed expectations and reminders of $\mathrm{MI}$ training, concepts of $\mathrm{MI}$ that were relevant for the daily work of $\mathrm{CHW}$, and the possibilities and challenges of MI. The CHW expressed the connections of learning at the time of MI training to work as well as personal life situations. Challenges were identified in the application of $\mathrm{Ml}$ for time-related issues to conduct domestic visits, intense daily work demands, changes in the work process, and administrative activities. MI was proven to be an appropriate and feasible tool for the professional practice of $\mathrm{PH}$.
\end{abstract}

Keywords: Motivational interviewing. Community health workers. Primary healthcare. Brazilian Health System.

\title{
ENTREVISTA MOTIVACIONAL COMO UNA HERRAMIENTA EN EL PROCESO DE TRABAJO DEL AGENTE COMUNITARIO DE SALUD
}

\section{Resumen}

La entrevista motivacional (EM) se caracteriza por una forma refinada de guiar una conversación mediante estrategias específicas que buscan estimular cambios de comportamiento. Esta investigación tuvo como objetivo comprender la apropiación de los 
Revista Baiana de Saúde Pública conceptos y técnicas de la EM por agentes comunitarios de salud después de un entrenamiento específico, realizado en un servicio de atención primaria de salud (APS) en la región Sur de Brasil. Es un estudio de enfoque cualitativo que incluyó la participación de agentes comunitarios de salud (ACS) en un grupo focal. El material textual producido fue analizado por la técnica del análisis temático de contenido. Las tres categorías que emergieron del grupo focal destacaron expectativas y recuerdos del entrenamiento en EM, conceptos de la EM con significados para el cotidiano de trabajo del ACS y posibilidades y desafíos de la EM. Los ACS expresaron conexiones de los aprendizajes en el momento del entrenamiento sobre EM a las situaciones de trabajo y de vida personal. Los desafíos se identificaron en la aplicación de la EM por cuestiones relacionadas con el tiempo para realizar una visita domiciliaria, la intensa demanda en el trabajo diario, los cambios en el proceso de trabajo y la realización de actividades administrativas. La EM se mostró una herramienta apropiada y viable para la práctica profesional de los ACS en el contexto de la APS.

Palabras clave: Entrevista motivacional. Agentes comunitarios de salud. Atención primaria de salud. Sistema Único de Salud.

\section{INTRODUÇÃO}

No Brasil, a Estratégia Saúde da Família (ESF) tem como objetivo reconstruir a prática da atenção primária à saúde (APS) e garantir o acesso à saúde para todas as pessoas. A APS é definida como primeiro nível de contato com os serviços, constituindo o início de um processo hierarquizado de atenção. Deve ser orientada de acordo com os seguintes princípios: primeiro contato, longitudinalidade, integralidade, coordenação do cuidado, abordagem familiar e enfoque comunitário ${ }^{1}$. A equipe da ESF é composta, minimamente por um médico, um enfermeiro, um auxiliar de enfermagem ou técnico de enfermagem e os agentes comunitários de saúde (ACS). A equipe pode ser ampliada com a incorporação de profissionais de odontologia: cirurgião-dentista, auxiliar e/ou técnico de saúde bucal².

O agente comunitário de saúde é um trabalhador que faz parte da equipe da comunidade onde mora. É uma pessoa preparada para orientar famílias sobre cuidados com sua própria saúde e com a da comunidade ${ }^{3}$. É considerado um personagem-chave na organização da assistência, uma vez que assume posição bidirecional, pois, ao mesmo tempo em que é morador da comunidade em que trabalha, é integrante da equipe de saúde ${ }^{4}$. De acordo com a orientação do Ministério da Saúde, os principais instrumentos de trabalho 
do ACS são a entrevista, o cadastramento das famílias, o mapeamento da comunidade, as reuniões comunitárias e a visita domiciliar, sendo esta última considerada uma de suas principais atividades ${ }^{5}$.

O ACS é considerado um ator diferenciado por ser um trabalhador genérico, de identidade comunitária e que atua muito além das questões de saúde puramente biológicas ${ }^{6}$. A atuação do ACS favorece não só o entendimento para diminuir o processo de adoecimento, levando em consideração os determinantes sociais, mas também a construção de ações de promoção de saúde baseadas nas reais necessidades da população .

As ações educativas também são desenvolvidas pelos ACS e devem visar, por exemplo, a proposição de mudanças de hábitos, comportamentos alimentares e higiênicos, entre outros, que encontram certa resistência por grande parte da população ${ }^{8}$. Por essa razão, é imprescindível o desenvolvimento de estratégias alternativas que aumentem a motivação do paciente com o seu cuidado em saúde. Estas "estratégias" podem ser utilizadas de diversas formas e em diferentes momentos, como as visitas domiciliares, mas de qualquer forma significam o reconhecimento de que não pode haver uma imposição por parte do profissional ${ }^{6}$.

Dentro dessa atmosfera de aceitação e empatia, a entrevista motivacional (EM) surge como uma forma refinada de guiar uma conversa visando a estimular a mudança do comportamento 9 . Apresenta-se como abordagem diretiva, centrada no indivíduo, respeitando sua autonomia e utilizando estratégias específicas que direcionem a conversa para exploração e resolução de sua ambivalência ${ }^{9-13}$.

A EM consiste basicamente em quatro técnicas iniciais específicas descritas como perguntas abertas, afirmação (reforço positivo), escuta reflexiva, resumo e fornecimento de informações, desde que o paciente as solicite ${ }^{10,14}$. Possivelmente, a escuta reflexiva seja a habilidade mais desafiadora da entrevista motivacional, pois é uma maneira de verificar, em vez de pressupor, que se foi entendido o que o paciente quis dizer ${ }^{15}$. O ouvinte reflexivo, na verdade, forma uma inferência razoável quanto ao sentido original daquilo que foi dito e dá voz a essa inferência sob a forma de uma afirmação. Por trás de todos estes aspectos técnicos, há uma noção simples: escutar envolve postura de interesse e aceitação para com o paciente enquanto o profissional está envolvido no processo $^{16}$.

No entanto, na maioria das vezes, o foco está voltado para o "espírito" da EM baseado na empatia, colaboração, evocação e autonomia do paciente ${ }^{17}$. A EM mostra-se como uma abordagem adaptável a cada pessoa, cultura e problema, sendo possível de ser ensinada em um treinamento adequado 9 . Nesse sentido, os princípios e técnicas da EM se aproximam em muitos aspectos aos do SUS e da APS, podendo, inclusive, ser utilizada por profissionais da 
Revista Baiana de Saúde Pública saúde que culturalmente estão acostumados ao uso de abordagens prescritivas e convencionais. Em uma revisão sistemática da literatura sobre o uso da EM no contexto da APS, os autores concluem que os profissionais podem se apropriar dos princípios e técnicas da EM por meio de treinamento específico e que os resultados podem ser positivos em pacientes de ambos sexos, qualquer idade e condição de saúde ${ }^{12}$.

Na EM a meta final é aumentar a motivação intrínseca do paciente de modo que a necessidade de mudança não seja imposta pelo profissional. As estratégias da abordagem, portanto, são mais persuasivas do que coercitivas, mais encorajadoras do que argumentativas ${ }^{13,14}$, possibilitando a construção de relações de vínculo entre usuários/famílias e profissionais da saúde pela conexão empática genuína às experiências "reais", das pessoas ${ }^{18}$.

Enquanto estratégia essencial às práticas de cuidado na APS, o vínculo é uma tecnologia leve, relacional que consiste na construção de relações de afetividade e confiança entre usuários/famílias e trabalhadores da saúde, permitindo o aprofundamento do processo de corresponsabilização pela saúde, construído ao longo do tempo, tendo, assim, um potencial terapêutico ${ }^{18-21}$. Espera-se, nesse sentido, que o uso da EM possa qualificar e ampliar as possibilidades de vínculo entre os usuários e os ACS.

A partir da relevância dessas reflexões no contexto da APS e compreendendo o papel estratégico do ACS, este estudo teve como objetivo compreender a apropriação dos conceitos e técnicas da entrevista motivacional por parte dos agentes comunitários de saúde após treinamento sobre EM realizado em um serviço de APS localizado no Sul do Brasil.

\section{MATERIAL E MÉTODOS}

O presente estudo trata-se de uma pesquisa qualitativa realizada no Serviço de Saúde Comunitária do Grupo Hospitalar Conceição (SSC-GHC), localizado no município de Porto Alegre, Rio Grande do Sul, Brasil. Integram esse serviço 12 unidades de APS compostas por equipes multiprofissionais (médicos, enfermeiros, dentistas, psicólogos, assistentes sociais, nutricionistas, farmacêuticos, técnicos de enfermagem, técnicos de saúde bucal e ACS). Esta pesquisa está associada a um conjunto de estudos que vem sendo realizado sobre a temática de entrevista motivacional, visto que o SSC-GHC busca o aprimoramento constante de ferramentas que qualifiquem a atenção à saúde. A EM mostrou-se como uma possível tecnologia leve e adequada à proposta da atenção primária em saúde ${ }^{10,12,22}$, o que incentivou os pesquisadores a organizar treinamentos básicos de EM inicialmente para profissionais de nível superior e, posteriormente, para profissionais técnicos e agentes comunitários de saúde, visto que a EM é uma abordagem transversal e aplicável à prática cotidiana de diferentes profissionais da saúde ${ }^{9,10}$. 
Os resultados aqui tecidos estão associados ao treinamento realizado especificamente para os ACS, sendo estes os protagonistas da pesquisa. Os encontros aconteceram em horário de trabalho, totalizando carga horária de 12 horas, dividido em três turnos de quatro horas, conforme combinação e autorização prévia das chefias e gerência do SSC-GHC, associada à disponibilidade dos profissionais. O treinamento visou à aprendizagem ativa dos princípios básicos da EM, contemplando orientações práticas para o uso de habilidades de comunicação empática, o uso de escuta reflexiva para trabalhar com a resistência e ambivalência, o desenvolvimento da discrepância, a escuta e a "conversa sobre mudança". O treinamento foi baseado no referencial teórico de Moyers et $\mathrm{a}^{23,24}$. Foi desenvolvida uma combinação de exposição dialogada, estudos de casos, vídeo e exercícios em duplas e em pequenos grupos. Dos 28 ACS que participaram do treinamento, 82\% eram mulheres, possuíam idade média de 43,3 anos, $71 \%$ deles tinham menos de 5 anos de experiência de trabalho e os demais, 10 anos de trabalho na área.

Os ACS que receberam o treinamento foram convidados a participar, após um ano, de um segundo encontro para manutenção e revisão dos conhecimentos sobre EM adquiridos no treinamento inicial. A adesão dos ACS nesse segundo momento foi significativa, tanto em relação ao número de profissionais presentes (17 participantes) como na participação ativa por meio de depoimentos, recordações e exemplos práticos do cotidiano de trabalho na aplicação da EM. Nesse encontro, emergiram múltiplos significados sobre a EM, especialmente em relação à postura profissional, que vão ao encontro do "espírito" da entrevista motivacional. As memórias dos ACS um ano após o treinamento expressas por palavras-chave (chuva de ideias) estão apresentadas no Quadro 1:

Quadro 1 - Conceitos, ideias, expressões que os ACS lembraram um ano após o treinamento sobre entrevista motivacional

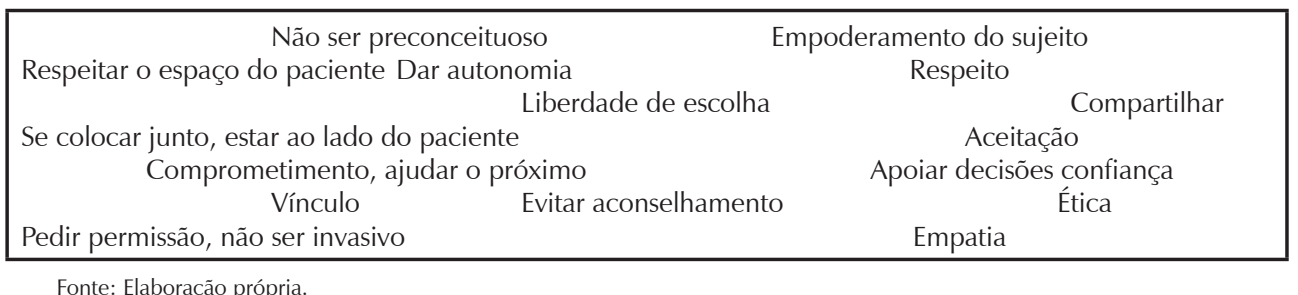

Considerando-se o objetivo proposto pela pesquisa, um estudo de abordagem qualitativa foi realizado uma vez que a intenção era trabalhar com o universo de significados da EM no grupo de trabalhadores da saúde vivendo em tempo e lugar específicos, o que 
Revista Baiana de Saúde Pública corresponde a um espaço mais profundo das relações, dos processos e dos fenômenos que não podem ser reduzidos à operacionalização de variáveis ${ }^{25}$. Nesse sentido, para a produção das informações, optou-se pelo desenvolvimento e análise de um grupo focal (GF).

O encontro do grupo focal ocorreu em junho de 2017, previamente agendado, com duração de duas horas, dentro do horário de trabalho dos ACS. Contou com a participação de cinco ACS (dois homens e três mulheres) pertencentes a quatro unidades de saúde diferentes, um moderador com experiência em pesquisa qualitativa e um observador. Os critérios de inclusão para participar do GF foram a participação no treinamento inicial e na revisão após um ano, a disponibilidade e o interesse na temática. Utilizou-se um roteiro previamente elaborado que norteou a discussão. $\mathrm{O}$ encontro foi registrado por meio de gravador de áudio, permitido pelos participantes e posteriormente transcrito.

A técnica de análise de dados utilizada nesta pesquisa foi a análise temática de conteúdo ${ }^{26}$. Inicialmente, foi realizada a leitura flutuante da produção textual, seguida por uma leitura exaustiva do material e organização em eixos temáticos, dos quais emergiram categorias de análise. As categorias foram construídas à luz do referencial teórico da EM¹4,16.

A pesquisa foi aprovada pelo Comitê de Ética em Pesquisa do GHC, registrada na Plataforma Brasil pelo número de CAAE 62658616.6.0000.5530, respeitando os preceitos éticos dispostos na Resolução CNS no 466/2012. No primeiro momento do GF, os participantes leram e assinaram o Termo de Consentimento Livre e Esclarecido.

\section{RESULTADOS E DISCUSSÃO}

Com base nas falas e reflexões trazidas pelo grupo focal, buscou-se compreender, a partir da percepção dos agentes comunitários de saúde, o significado da entrevista motivacional em sua prática cotidiana de trabalho na APS. Os resultados estão apresentados em quatro categorias emergentes, quais sejam: (1) o treinamento em entrevista motivacional: expectativas e lembranças de momentos intensos de troca e de aprendizagem; (2) aprendendo sobre a entrevista motivacional: conceitos com significados para o cotidiano de trabalho dos ACS; (3) as (im)possibilidades do aprender no trabalho em equipe; e (4) a entrevista motivacional no cotidiano de trabalho dos agentes comunitários: possibilidades e desafios do lidar com vidas.

\section{O TREINAMENTO EM ENTREVISTA MOTIVACIONAL: EXPECTATIVAS E} LEMBRANÇAS DE MOMENTOS INTENSOS DE TROCA E DE APRENDIZAGEM

O treinamento em entrevista motivacional tem sido sugerido como uma ferramenta que visa à promoção de mudanças aplicáveis à prática cotidiana do profissional 
que está inserido na atenção primária ${ }^{12}$. Estudos mostram a aplicação da EM com resultados positivos no manejo e tratamento de situações sensíveis da APS como dependência química, cessação do tabagismo, perda de peso, incentivo à atividade física e tratamento de asma e diabetes ${ }^{9,12,13,16}$.

Portanto, os profissionais do SSC-GHC de Porto Alegre, Rio Grande do Sul receberam o treinamento sobre EM com o intuito de qualificar o cuidado e o planejamento das ações de saúde. A inserção da educação permanente para profissionais da saúde, incluindo os Agentes Comunitários de Saúde, surge como uma estratégia para repensar e reorganizar os processos de trabalho ${ }^{27,28}$. Os ACS lembram a expectativa que estavam em participar do treinamento, uma vez que sabiam que colegas de outros núcleos profissionais já o haviam realizado.

"Quando eu soube do curso, eu já tinha criado uma expectativa antes disso, porque eu tinha ficado sabendo que outros profissionais, colegas de outros núcleos, já haviam feito. Aí então eu queria fazer, só que a minha categoria profissional não tinha sido chamada ainda." (Grupo focal).

Na percepção dos ACS, o interesse pelo treinamento advinha da possibilidade de aprender maneiras melhores de manejar, orientar e conduzir os pacientes de sua área, oportunizando novos elementos para aprimorar sua prática cotidiana. Essa qualificação é relevante para o trabalho do ACS, visto que suas atribuições estão relacionadas à orientação e ao incentivo da comunidade ${ }^{29}$.

“Então eu estava bem curioso em relação a isso: o que eu poderia aprender para que eu pudesse manejar melhor, orientar, como eu poderia conduzir melhor o paciente." (Grupo focal).

A proposta inicial do treinamento para os ACS era a mesma para os demais profissionais, ou seja, dois encontros com uma carga horária total de oito horas. No entanto, conforme relembraram os participantes do GF, foram momentos "bastante intensos" e com "bastante troca", sendo necessários mais encontros para "aprender mais". Foi uma demanda exclusiva dessa categoria profissional. O treinamento foi, por fim, concluído após três encontros, com carga horária total de 12 horas. 
Revista Baiana de Saúde Pública
"Foi uma proposta que tivemos para ampliar, porque a gente entendeu que no encontro tiveram vários momentos para aprender e trocar, mas foi muito intensa a troca." (Grupo focal).

Observa-se nos relatos do grupo a expectativa dos ACS em realizar o curso, pois a ideia do treinamento remete ao aprendizado de novas formas de abordagem aplicável às práticas realizadas em seu cotidiano de trabalho. Essa expectativa, na percepção dos ACS, refletiu-se nos encontros, os quais foram ampliados para mais um dia, pois foram considerados intensos e de grande oportunidade para trocas de experiências entre os participantes.

APRENDENDO SOBRE A ENTREVISTA MOTIVACIONAL: CONCEITOS COM SIGNIFICADOS PARA O COTIDIANO DE TRABALHO DOS ACS

A Entrevista Motivacional tem como principal objetivo auxiliar as pessoas a realizar mudanças de comportamento mal adaptativo à medida que aumenta a motivação intrínseca pela exploração e resolução da sua ambivalência ${ }^{9-13}$. "Orientar, mas à medida que o paciente vai trazendo também" com vistas a fortalecê-lo. Conforme trazido pelos ACS no GF, é preciso que o profissional respeite a realidade e o processo de mudança de cada indivíduo, resistindo ao reflexo de "consertar as coisas"16, pois "a realidade dele é outra, então tem que deixar ele 'aberto' para ele enxergar o que é melhor para a vida dele".

"Não parte do terapeuta, por exemplo, a solução do melhor tratamento para o paciente, mas parte do próprio paciente. As expressões do que ele está proposto a mudar. Então, nesse contexto, somou bastante os encontros da entrevista motivacional." (Grupo focal).

O grupo reiterou que o treinamento EM trouxe a questão do saber ouvir e escutar, "deixar o nosso interlocutor falar mais". A abordagem da EM mostrou desenvolver a maneira de escutar e agir com os pacientes, demandando ao profissional uma escuta atenta para compreender os motivos do usuário para a necessidade de mudança, os benefícios que ele entende que a mudança poderia trazer e como ela seria bem-sucedida se acontecesse ${ }^{17}$. De acordo com os ACS, para colocar em prática os conhecimentos adquiridos é necessário um ambiente adequado e tranquilo, caso contrário pode dificultar a aplicação das técnicas da EM. 
"Primeiro o paciente fala, tem que incentivar o paciente a dizer o que ele está pensando: da doença, do fato de ele ter que usar tantas medicações, da importância de levar o tratamento adiante, de cumprir as consultas etc. Tem que ter paciência e tempo para escutar isso, pra pode explicar mais um pouquinho. [...] Para tentar fazer uma escuta reflexiva ali é difícil, porque as pessoas falam gritando e eu tenho que cuidar porque numa casa a pessoa tem soro positivo e na outra o rapaz é etilista pesado." (Grupo Focal).

Por intermédio da escuta reflexiva na EM, o profissional busca aceitar a perspectiva do indivíduo sem criticá-lo, sem julgá-lo e sem culpá-lo, assumindo a ambivalência como parte do processo de mudança ${ }^{14}$. Esse conceito foi reforçado pelo GF no sentido de colocar-se "mais no lugar do paciente, ter mais paciência", de forma a "não criticar", procurando junto a ele uma solução para os problemas ou, pelo menos, para "tentar amenizá-los". Essa atitude de aceitação, demonstrada pelos ACS, com respeito e compreensão, estimula uma aliança terapêutica e a autoestima do paciente, o que se configura uma condição importante para a mudança ${ }^{30}$.

"A gente trabalha bem essa questão da ambivalência do paciente, tentar entender porque ele tem umas barreiras, o que vai motivar ele a fazer mudança e quais as dificuldades que ele tem para a mudança e com essas informações eu poder trabalhar em cima disso para planejar o cuidado dele." (Grupo Focal).

Outro conceito que perpassou as falas no GF e está inserido no referencial teórico da EM é a construção da parceria mútua entre profissional e paciente para que se tenha bons resultados na aplicação da $\mathrm{EM}^{12}$. "E aí o paciente se torna teu amigo e vai levando o tratamento cada vez mais a sério." Sendo assim, desenvolver um bom relacionamento dá ao paciente a confiança necessária para ser honesto e falar abertamente do problema ${ }^{17}$. A dinâmica social que se constrói pelo fato de o ACS estar inserido na comunidade onde vive e trabalha permite que seus sentimentos e escutas influenciem seu agir, de forma a estabelecer diálogo e favorecer o estreitamento de vínculos e aliança terapêutica ${ }^{4}$. Dessa forma, se estabelece uma relação próxima, com significado, baseada no diálogo, na confiança e no afeto, refletindo-se no modo como as pessoas entendem o cuidado em saúde, conforme expresso na fala do GF:

“Estou passando no corredor e vejo aquela mulher chorando, desesperada. Daí eu sentei ao lado dela, dei água e pedi para ela me contar o porquê que ela estava 
Revista Baiana de Saúde Pública soluçando. Daí ela trouxe a vida dela e eu disse para ela refletir e sentar com a família para conversar e ver o que realmente aconteceu. Tem essa questão do afeto que a nossa profissão traz. Uma simples expressão de olhar que o paciente retribua para nós, que ele traga essa devolutiva para nós, já entendemos que a partir dali gerou um elo e começa uma nova caminhada chamada vínculo." (Grupo focal).

Observa-se, portanto, que as recordações do GF estão fortemente mais relacionadas ao conhecimento e aplicação do "espírito" da EM e seus preceitos básicos, como a empatia, o vínculo, o apoio, a motivação. Nesse sentido, os ACS levaram a EM para seus cotidianos de trabalho, agregando uma postura diferenciada de como escutar e agir frente às complexidades das situações de vida dos usuários, aspectos relevantes para o trabalho dos ACS na APS.

\section{AS (IM)POSSIBILIDADES DO APRENDER NO TRABALHO EM EQUIPE}

A importância da educação permanente na qualificação do trabalho é expressa pelos ACS, pois, assim como os demais profissionais da saúde, eles necessitam desenvolver competências, como a comunicação com a comunidade, o olhar vigilante e o bom relacionamento interpessoal, uma vez que a orientação e a educação em saúde são atribuições desse profissional².

“A gente sempre está disposto a estar recebendo orientações e aprendendo cada vez mais, isso trouxe muito para nós. Quando começa as capacitações, a gente começa a ver outra realidade. É conversa, é comunicação, são pessoas que tem orientação pra te dar, porque a gente está aqui para aprender." (Grupo focal).

No entanto, os ACS relatam desafios na participação da equipe dos processos de educação permanente, o que passa por fragilidades no "querer fazer" e na "falta de motivação". De acordo com os ACS, "seria essencial que todos os profissionais fizessem o treinamento".

"Eu acho que todos os profissionais deveriam fazer isso. A gente trabalha em equipe e vão ter sempre aqueles que não concordam, não tão a fim, não querem nesse momento. O querer fazer também faz parte da motivação e faz parte da vida. Pessoas que estão pensando como a gente e pessoas que não estão pensando como a gente." (Grupo Focal). 
Relatam ainda "a falta de entendimento" dos profissionais de que "é pro nosso bem e do paciente" realizar as oficinas de entrevista motivacional. Um caminho para sensibilizar as equipes é proposto pelo grupo com o intuito de motivar mais profissionais para que se inscrevam, realizem e participem dos treinamentos. "Então sensibilizar pode ser o caminho." No entanto, não se pode esquecer que essa sensibilização é afetada pela cultura e formação de cada categoria profissional. Nem sempre o estilo da EM se ajusta ao modo de fazer de todos os trabalhadores que muitas vezes preferem o modelo prescritivo e hierárquico na abordagem dos usuários, e isso precisa ser respeitado.

A proposta que emergiu foi a possibilidade de levar o curso às reuniões de equipe que acontecem semanalmente em todas as unidades de saúde do SSC-GHC. "No horário da reunião de equipe, usar um dia ou dois. Mesmo que desse para passar mais resumido, mas daí seria com todos." Percebe-se, entretanto, na fala dos ACS, certo receio em sugerir assuntos para as reuniões semanais de equipe que estejam fora da pauta e, até mesmo, dificuldade de sentir-se parte integrante do grupo, e assim poder sugerir temas e propostas para qualificar o processo de trabalho.

"É que tudo tem que ser meio pactuado, porque a gente sabe que o espaço para as reuniões de equipe é um espaço que as equipes já têm seus assuntos. Então tem que tomar muito cuidado para que não seja uma imposição. [...] Eu acho que todos os profissionais da nossa área são competentes, o que falta é mais oportunidade pra gente falar, pra gente expor as coisas, pra gente impor. Faltam para nós espaços para a gente 'botar para fora' e fazer as coisas realmente acontecerem." (Grupo focal).

De acordo com a revisão de literatura ${ }^{28}$, é necessária a instauração de processos de qualificação para os ACS por meio de capacitações elaboradas com métodos de ensinoaprendizagem inovadores, que despertem a reflexão e a crítica e baseados no desenvolvimento e aprimoramento de suas atribuições, cujos objetivos sejam transformá-los em sujeitos próativos. Nesse sentido, cabe aos gestores, chefias e demais profissionais das unidades de saúde dar voz aos ACS a fim de empoderá-los e potencializar sua atuação no território e na equipe.

Uma questão importante a se considerar na implementação da entrevista motivacional nas políticas públicas e de educação permanente para ACS e demais profissionais do SUS e da APS é o custo desse processo. O treinamento para o uso da EM requer um profissional capacitado e habilitado, espaço físico para comportar em média 30 participantes e dispensa dos trabalhadores para participar de, pelo menos, oito horas de formação. Portanto, os custos estão relacionados basicamente a carga horária de trabalho dos trabalhadores. 
Revista Baiana de Saúde Pública

\section{AGENTES COMUNITÁRIOS: POSSIBILIDADES E DESAFIOS DO LIDAR COM VIDAS}

O ACS é um profissional estratégico nas equipes de saúde, pois constrói o elo entre a comunidade e a unidade ${ }^{4,6}$, com aproximação e contato com as famílias, o que permite compreender as necessidades daqueles que habitam na sua área de abrangência ${ }^{29}$. Os relatos do GF reforçam esse papel do ACS, destacando o grande potencial in loco do trabalho desse profissional.

“Nós lidamos com vidas, saúde, temos que estar preparados para o que vier [...] tu tem que entrar numa casa e saber se o paciente comeu, se o paciente não comeu, porque não está tomando o remédio etc. Então tem que ver a tua rede, o que tu podes resgatar pra tentar dar uma força para ele para tentar ser motivado a fazer aquele tratamento." (Grupo focal).

Para os ACS, o aprender sobre a EM remete ao aprendizado de uma "forma melhor", "uma forma diferente", "mais positiva" de manejar e orientar os pacientes. O aprendizado serviu para qualificar e fortalecer o trabalho do ACS, trazendo "mais estrutura e firmeza nos seus alicerces" de conhecimento.

"A gente aprende com cada paciente, com cada usuário que a gente consiga orientar bem e motivar ele a fazer o autocuidado. Isso não tem preço, porque está associado à vida dele. [...] Com o curso eu posso lidar melhor com as objeções, eu posso trabalhar melhor com o paciente, de uma maneira mais fácil, mais compreensiva." (Grupo focal).

Apesar de os ACS terem apropriado os conceitos da EM, nem sempre é possível aplicá-la. Aspectos relacionados ao tempo para realizar uma visita domiciliar contemplando os preceitos da EM, a intensa demanda no cotidiano e as mudanças no processo de trabalho foram relatados como desafios pelo grupo focal. Além disso, é trazido pelo GF a questão de realizar atividades administrativas - "quando não temos que fazer o trabalho de administrativo também" -, como atuação na recepção da unidade, agendamento de consultas, organização de pastas e prontuários, controle de materiais e almoxarifado ${ }^{31}$. 
"A gente redivide a área toda vez que algum ACS sai. Daí tu fica cada vez com mais pessoas. [...] Tu precisa buscar uma gestante faltosa ou vacina das crianças faltosas... E assim a gente vive nosso dia a dia. Primordialmente as emergências, as coisas mais obrigatórias, e a medida do possível tu vai fazendo o reconhecimento da área, recadastro entre outras coisas, [...] como é tudo muito corrido, a gente já está pensando que tem outra coisa para fazer, as coisas do administrativo por exemplo." (Grupo focal).

Percebe-se nas falas um sentimento de ausência, frustração e isolamento quando se fala sobre o trabalho em rede, visto que nem sempre o ACS recebe a supervisão e o apoio da sua equipe ${ }^{4}$. O processo de trabalho da unidade de saúde deve objetivar que tanto os ACS como os demais profissionais da equipe andem em consonância, formando uma rede "forte, não fraca, que dê apoio" para promover o cuidado integral. Sentimentos como desmotivação, frustração e angústia diante da incapacidade de resolução de problemas e da falta de parcerias marcaram os relatos do grupo. A dificuldade dos ACS em encontrar respostas positivas aos encaminhamentos de maior complexidade solicitados ao serviço de saúde pode dificultar seu papel de mediador e resultar em uma perda de legitimidade perante a comunidade, o que gera desestímulo para o desempenho de suas ações ${ }^{6}$. O entendimento dos ACS é que, se a rede funcionar, o trabalho da equipe será muito mais resolutivo para o usuário.

“Às vezes, tu está motivado, mas tu te desmotiva, porque tu chega na Unidade e não consegue a solução. [...] Na hora que tu tem que contar com alguém para finalizar, tu não consegue. Então é complicado, porque tu morre na praia. Não resolve nada. Nós nos sentimos frustrados, com mãos atadas, porque nosso trabalho não depende só de nós. [...] No momento que a rede funcionar vai ser uma maravilha, mais ainda vai melhorar." (Grupo Focal).

Destacam ainda que os ensinamentos adquiridos ultrapassam o mundo do trabalho e podem ser aplicados em diferentes âmbitos de suas vidas, como em casa, com suas famílias e amigos - "quem faz esse curso vai aplicar para o resto da vida".

\section{CONSIDERAÇÕES FINAIS}

A EM tem sido considerada uma ferramenta efetiva nos cuidados da atenção primária ${ }^{12}$ e, portanto, a procura por formação em pelos profissionais da área da saúde tem aumentado significativamente. Nesse sentido, o SSC-GHC organizou treinamentos básicos inicialmente para 
Revista Baiana de Saúde Pública profissionais de nível superior e, posteriormente, para profissionais técnicos e agentes comunitários de saúde. Este trabalho buscou compreender a apropriação dos conceitos e técnicas da entrevista motivacional dos agentes comunitários de saúde um ano após receberem o treinamento.

As percepções que emergiram do grupo focal mostraram que os ACS, mesmo após um ano, percebem a aplicação dos conceitos e técnicas do treinamento da entrevista motivacional em sua prática de trabalho e em outros âmbitos de suas vidas, como em casa, com suas famílias e amigos. Além disso, observou-se que as memórias estiveram mais relacionadas ao ensino do "espírito" da EM, demonstrando que é possível conectar os aprendizados com a prática cotidiana pela postura diferenciada de como escutar e agir perante as situações, praticar a comunicação empática, desenvolver o vínculo e fornecer apoio para motivar seus pacientes e suas famílias. Os ACS reiteram a importância de toda a equipe em se apropriar dos conceitos e técnicas da EM, visto que compreenderam a potencialidade do treinamento para trazer mudanças no processo de trabalho de todos os profissionais, no sentido de fornecer "visão mais ampla" lidar com os indivíduos e a comunidade.

Entretanto, desafios foram relatados pelo GF para aplicação da EM no cotidiano de trabalho. Aspectos relacionados ao tempo para realizar uma visita domiciliar, a intensa demanda de trabalho, mudanças no processo e realização de atividades administrativas foram trazidos pelos ACS. Apesar dos desafios relatados, a entrevista motivacional mostrou-se uma ferramenta apropriada e viável para a prática profissional dos ACS no contexto da APS.

\section{COLABORADORES}

1. Concepção do projeto, análise e interpretação dos dados: Gabriela de Luca Meyer, Ramona Fernanda Ceriotti Toassi, Elisabeth Meyer e Daniel Demétrio Faustino-Silva.

2. Redação do artigo e revisão crítica relevante do conteúdo intelectual: Gabriela de Luca Meyer, Ramona Fernanda Ceriotti Toassi, Elisabeth Meyer e Daniel Demétrio Faustino-Silva.

3. Revisão e/ou aprovação final da versão a ser publicada: Gabriela de Luca Meyer, Ramona Fernanda Ceriotti Toassi, Elisabeth Meyer e Daniel Demétrio Faustino-Silva.

4. Ser responsável por todos os aspectos do trabalho na garantia da exatidão e integridade de qualquer parte da obra: Gabriela de Luca Meyer, Ramona Fernanda Ceriotti Toassi, Elisabeth Meyer e Daniel Demétrio Faustino-Silva.

\section{REFERÊNCIAS}

1. Starfield B. Atenção primária: equilíbrio entre necessidades de saúde, serviços e tecnologia. Brasília (DF): Unesco/Ministério da Saúde; 2002. 
2. Brasil. Decreto no 3.189, de 4 de outubro de 1999. Fixa diretrizes para o exercício da atividade de Agente Comunitário de Saúde (ACS), e dá outras providências. Diário Oficial [da] República Federativa do Brasil, Brasília (DF): 1999 out 5. Seção 1, p. 1.

3. Brasil. Ministério da Saúde. O trabalho do agente comunitário de saúde. Brasília (DF); 2009.

4. Peres CRF, Caldas AL Jr, Silva RF, Marin MJS. Ser agente comunitário de saúde: motivação e significado. REME Rev Min Enferm. 2010;14(4):559-65.

5. Brasil. Ministério da Saúde. Guia prático do Programa Saúde da Família. Brasília (DF); 2001.

6. Bornstein VJ, Stotz EN. Concepções que integram a formação e o processo de trabalho dos agentes comunitários de saúde: uma revisão da literatura. Ciênc Saúde Colet. 2008;13(1):259-68.

7. Nogueira ML, Oliveira MGA, Morel AP, Lopes MCR. A educação popular em saúde como base da preceptoria na formação técnica de agentes comunitários de saúde. Rev APS. 2015;18(4):438-46.

8. Nunes, MO, Trad LB, Almeida BA, Homem CR, Melo MCIC. O agente comunitário de saúde: construção da identidade desse personagem híbrido e polifônico. Cad Saúde Pública. 2002;18(6):1639-46.

9. Souza FP, Silva EM, Boff RM, Trindade MT, Oliveira MS. Características do treinamento em entrevista motivacional. Aletheia. 2012;1(38-39):186-95.

10. Östlund AS, Wadensten B, Kristofferzon ML, Haggström E. Motivational interviewing: experiences of primary care nurses trained in the method. Nurse Educ Pract. 2012;15(2):111-8.

11. Curry-Chiu ME, Catley D, Voelker MA, Bray KK. Dental hygienists' experiences with motivational interviewing: a qualitative study. J Dent Educ. 2015;79(8):897-906.

12. VanBuskirk KA, Wetherell JL. Motivational interviewing with primary care populations: a systematic review and meta-analysis. J Behav Med. 2014;37(4):768-80.

13. Rubak S, Sandbæk A, Lauritzen T, Christensen B. Motivational interviewing: a systematic review and meta-analysis. Br J Gen Pract. 2005;513(55):305-12.

14. Miller WR, Rollnick, S. Motivational interviewing: helping people change. 2a ed. New York: Guilford Press; 2012.

15. Miller WR, Rollnick S. Entrevista motivacional: preparando as pessoas para a mudança de comportamentos adictivos. Porto Alegre (RS): Artmed; 2001. 
Revista Baiana de Saúde Pública
16. Rollnick S, Miller WR, Butler CC. Entrevista motivacional no cuidado da saúde: ajudando pacientes a mudar comportamento. Porto Alegre (RS): Artmed; 2009.

17. Brobeck E, Odencrants S, Bergh H, Hildingh C. Patients' experiences of lifestyle discussions based on motivational interviewing: a qualitative study. BMC Nursing. 2014;13(13):1-7.

18. Barros RS, Botazzo C. Subjetividade e clínica na atenção básica: narrativas, histórias de vida e realidade social. Ciênc Saúde Colet. 2011;16(11):4337-48.

19. Monteiro MM, Figueiredo VP, Machado MFAS. Formação do vínculo no Programa de Saúde da Família numa Unidade Básica de Saúde. Rev Esc Enferm USP. 2009;43(2):358-64.

20. Pinheiro PM, Oliveira LC. A contribuição do acolhimento e do vínculo na humanização da prática do cirurgião-dentista no Programa Saúde da Família. Interface Comun Saúde Educ. 2011;15(36):187-98.

21. Brasil. Ministério da Saúde. Política Nacional de Atenção Básica. Brasília (DF); 2012.

22. Codern-Bové N, Pujol-Ribera E, Pla M, González-Bonilla J, Granollers S, Ballvé JL, et al. Motivational interviewing interactions and the primary health care challenges presented by smokers with low motivation to stop smoking: a conversation analysis. BMC Public Health. 2014;14:1225.

23. Moyers TB, Martin T, Christopher PJ, Houck JM, Tonigan JS, Amrhein PC. Client language as a mediator of motivational interviewing efficacy: where is the evidence? Alcohol Clin Exp Res. 2007;31(3):40-7.

24. Moyers TB, Martin T, Christopher PJ, Houck JM, Tonigan JS, Amrhein PC. From in-session behaviors to drinking outcomes: a causal chain for motivational interviewing. J Consult Clin Psychol. 2009;77(6):1113-24.

25. Minayo MCS, Deslandes SF, Cruz Neto O, Gomes R. Pesquisa social: teoria, método e criatividade. 21a ed. Petrópolis (RJ): Vozes; 2002.

26. Bardin L. Análise de conteúdo. Lisboa: Edições 70; 2011.

27. Noronha MGRCS, Cardoso PS, Moraes TNP, Centa ML. Resiliência: nova perspectiva na promoção da saúde da família? Ciênc Saúde Colet. 2009;14(2):497-506.

28. Gomes KO, Cotta RMM, Mitre SM, Batista RS, Cherchiglia ML. O agente comunitário de saúde e a consolidação do Sistema Único de Saúde: reflexões contemporâneas. Physis. 2010;20(4):1143-64. 
29. Costa MC, Silva EB, Jahn AX, Resta DG, Colom ICS, Carli R. Processo de trabalho dos agentes comunitários de saúde: possibilidades e limites. Rev Gaúcha Enferm. 2012;33(3):134-40.

30. Miller WR, Baca LM. Two-year follow-up of bibliotherapy and therapistdirected controlled drinking training for problem drinkers. Behav Ther. $1983 ; 14(3): 441-8$.

31. Ferraz $L$, Aerts DRGC. O cotidiano de trabalho do agente comunitário de saúde no PSF em Porto Alegre. Ciênc Saúde Colet. 2005;10(2):347-55.

Recebido: 20.4.2018. Aprovado: 25.9.2018. 